\title{
HEMOCULTURAS PARA O DIAGNOSTICO PARASITOLÓGICO NA FASE CRÔNICA DA DOENÇA DE CHAGAS *
}

\author{
Oto G. Mouräo* e Odeni C. Mello**
}

\begin{abstract}
Os autores apresentam o resultado de hemoculturas de 20 chagásicos crôninos, em meio LIT.

Usaram como inóculo o cancentrado de células de $10 \mathrm{ml}$ de sangue, lavado em solução fisiológica após remoção do plasma por centrifugação a 3.000 r.p.m. A papa, assim obtida, foi semeada em porções iguais em dois tubos contendo, cada um, $5 \mathrm{ml}$ de LIT.

Com uma unica hemocultura obtiveram 6 casos positivos (30\%). Números variáveis de hemoculturas, 1 a 14, nos 20 pacientes, possibilitaram a positividade de 9 casos (45\%). Submetendo 7 pacientes a 4 ou mais hemoculturas $(4,5,6$, 10 e 14), 5 dentre eles mostraram-se positivos $(71,4 \%)$.

Recomendam o método para a rotina por ser prático e de fácil execução.
\end{abstract}

\section{INTRODUÇÃO}

Embora em 1949 Pifano (9) tenha relatado 5 hemoculturas positivas em 80 chagásicos crônicos $(6,25 \%)$, o conceito que vem prevalecendo é o de que a hemocultura é impraticável na fase crônica da mo. léstia de Chagas. Para isto muito contribuiram os trabalhos de Freitas $(4,5,6) \mathrm{em}$ $1947,1952,1958$ que reiteradamente mostraram resultados negativos nos meios de Bonacci e N.N.N.

Em 1966 Chiari \& Brener (2), usando o LIT, obtiveram 9 casos positivos $(25,7 \%)$ em 35 portadores da doença de Chagas crônica. Para obter esses resultados semearam $15 \mathrm{ml}$ de sangue de cada paciente em 8 tubos, 3 com o sangue total, 3 com o sobrenadante e 2 com o sedimento de uma aliquota centrifugada.
Nesse mesmo ano, um de nós, Mourão (7), relatou, usando meio próprio, positividade de $83,3 \%$ em 50 pacientes. Esse trabalho, no entanto, é destituido de valor, porque ficou provado que o técnico, que colaborou na pesquisa, introduziu tripanosomas no meio.

Em 1972, Albuquerque e cols (1) relataram o resultado de hemoculturas seriadas de 38 casos, em meio de Warren, com positividade de $100 \%$. Nas nossas mãos, porém, o método não se reproduziu.

Conclui-se, portanto, que a hemocultura na fase crônica da moléstia de Chagas é possivel, podendo a positividade alcançar niveis de $25,7 \%$, conforme obtiveram Chiari e Brener (2)

O presente trabalho possibilita a cultura em apenas 2 tubos e procura aumentar essa positividade, pela remoção do plasma

\footnotetext{
* Trabalho realizado no Departamento de Clínica Médica da Faculdade de Medicina da U.F.M.G. Serviço de Investigaçăo da Doença de Chagas sob a direçáo do Prof. J. Romeu Cançado.

* Prof. Adjunto do Departamento de Clínica Médica da Faculdade de Medicina da U.F.M G.

* * Universitária da Faculdade de Medicina da U.F.M.G.

Recebido para publicaçăo em 18.4.75.
} 


\section{TA B E L A I}

CULTIVO DO TRYPANOSOMA CRUZI A PARTIR DE CÉLULAS SANGUÍNEAS, LAVADAS, DE CHAGÁSICOS CRÔNICOS POSITIVIDADE POR PACIENTE

\begin{tabular}{|c|c|c|c|c|c|c|c|c|c|c|c|c|c|c|}
\hline \multirow{2}{*}{ PACIENTES } & \multicolumn{14}{|c|}{ HEMOCULT $U$ M R A $S$} \\
\hline & 1 & 2 & 3 & 4 & 5 & 6 & 7 & 8 & 9 & 10 & 11 & 12 & 13 & \\
\hline & & & $\mathbf{P}$ & $\mathbf{P}$ & $\mathbf{N}$ & $\mathbf{P}$ & $\mathbf{P}$ & $\mathbf{N}$ & $r$ & $\mathbf{N}$ & $\mathbf{P}$ & $\mathbf{N}$ & $\mathbf{N}$ & $N$ \\
\hline & & & $\cdots$ & & $\cdots$ & $\cdots$ & $\cdots$ & $\cdots$ & $\cdots$ & $\cdots$ & $\cdots$ & $\cdots$ & $\cdots$ & \\
\hline & &.- & $\cdots$ & $\cdots$ & $\ldots$ & $-\cdots$ & $-\cdots$ & $\cdots$ & $+\cdots$ & --- & $-\cdots$ & 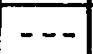 & $\ldots$ & - \\
\hline JP.C.C. & $\mathbf{N}$ & $\mathbf{P}$ & $\ldots$ & $-\ldots$ & $\ldots$ & $\overline{---}$ & --- & $-\cdots$ & $\cdots$ & --- & $\cdots$ & -- & $-\cdots$ & - \\
\hline & $\mathbf{N}$ & $\ldots$ & $\cdots$ & $-\cdots$ & $\cdots$ & $\cdots$ & $\cdots$ & $-\cdots$ & $-\cdots$ & --- & -- & $-\cdots$ & $\cdots$ & \\
\hline & 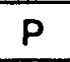 & $\mathbf{P}$ & $\mathbf{P}$ & $\cdots$ & $\cdots$ & & $\cdots$ & $\ldots$ & $\cdots$ & $\cdots$ & $\cdots$ & $\cdots$ & $\cdots$ & $\cdots$ \\
\hline & $\mathbf{N}$ & $P$ & $N$ & $N$ & $P$ & -- & $\ldots$ & $\ldots$ & $\ldots$ & $-\cdots$ & $\ldots$ & $\cdots$ & $\ldots$ & - \\
\hline.$v$. & $\mathbf{N}$ & $\mathbf{N}$ & $\mathbf{N}$ & $N$ & $\mathbf{N}$ & $N$ & $N$ & $\mathrm{~N}$ & $\mathbf{N}$ & $N$ & $\cdots$ & $\cdots$ & $\cdots$ & - \\
\hline .C.S. & IN & $\mathbf{N}$ & $N$ & $\cdots$ & $\cdots$ & $\ldots$ & $\cdots$ & $\cdots$ & $-\cdots$ & $\ldots$ & $\cdots$ & $\cdots$ & $\ldots$ & \\
\hline O.P.S. & 10 & $\cdots$ & $\cdots$ & $\cdots$ & $\cdots$ & $\cdots$ & $\cdots$ & $\cdots$ & $\cdots$ & $\cdots$ & $\cdots$ & $\ldots$ & $\ldots$ & \\
\hline & iv & $\mathrm{N}$ & $\mathbf{N}$ & $\cdots$ & $\cdots$ & $\cdots$ & $\cdots$ & $\cdots$ & $\ldots$ & $\cdots$ & $\cdots$ & $\ldots$ & $\cdots$ & $\cdots$ \\
\hline M.F.O. & $\mathbf{P}$ & $\mathbf{N}$ & $\cdots$ & $\ldots$ & $\ldots$ & $\ldots$ & $\cdots$ & $\cdots$ & $\ldots$ & $\cdots$ & $\cdots$ & $\cdots$ & $\cdots$ & - \\
\hline R.A.C. & $\mathbf{N}$ & $\mathbf{N}$ & $\cdots$ & $\ldots$ & $\ldots$ & $\ldots$ & $\ldots$ & $\ldots$ & $\ldots$ & $\cdots$ & $\cdots$ & $\cdots$ & $\cdots$ & \\
\hline S.A.O. & $\Lambda$ & $\mathbf{N}$ & $\mathbf{N}$ & $\mathbf{N}$ & $\mathbf{N}$ & $\cdots$ & $\cdots$ & $\cdots$ & $\cdots$ & $\cdots$ & $\cdots$ & $\cdots$ & $\cdots$ & $\therefore$ \\
\hline C. 0. & $N$ & $\mathbf{N}$ & $\mathbf{N}$ & $\cdots$ & $\cdots$ & $\cdots$ & $\cdots$ & $\cdots$ & $\cdots$ & $\cdots$ & $\cdots$ & $\cdots$ & $\cdots$ & $\cdots$ \\
\hline I.G.C. & $\mathbf{N}$ & $\mathbf{N}$ & $N$ & $\cdots$ & $\cdots$ & $\cdots$ & $\cdots$ & $\cdots$ & $\cdots$ & $\cdots$ & $\cdots$ & $\cdots$ & $\cdots$ & -- \\
\hline A. M. & $N$ & $N$ & $N$ & $N$ & $\mathbf{N}$ & $P$ & $\cdots$ & $\cdots$ & $\cdots$ & $\cdots$ & $\cdots$ & $\cdots$ & $\cdots$ & $\cdots$ \\
\hline A.F.M. & $P$ & $\mathbf{P}$ & $\mathbf{P}$ & $P$ & $N$ & $P$ & $\cdots$ & $\cdots$ & $\cdots$ & $\cdots$ & $\cdots$ & $\cdots$ & $\cdots$ & - \\
\hline F.F.S. & $N$ & $\mathrm{~N}$ & $N$ & $\cdots$ & $\cdots$ & $\cdots$ & $\cdots$ & $\cdots$ & $\cdots$ & $\cdots$ & $\cdots$ & $\cdots$ & $\cdots$ & - \\
\hline A.M.L. & $P$ & $N$ & $N$ & $N$ & $\cdots$ & \begin{tabular}{|l|}
$\cdots$ \\
\end{tabular} & $\cdots$ & $\ldots$ & $\ldots$ & $\cdots$ & $\cdots$ & $\cdots$ & $\cdots$ & - \\
\hline
\end{tabular}

$P=$ POSITIVA

$N=$ NEGATIVA

CADA HEMOCULTURA CONSTA DE 2 TUBOS CONTENDO CADA UM 5 ML DE LIT. E O CONCENTRADO DE CÉLULAS DE 5 ML DE SANGUE. 
e lavagem dos elementos figurados do sangue, na tentativa de eliminar ou pelo menos reduzir a ação de substâncias nocivas ao crescimento como: complemento, properdina, betalisina, lisozima e possivelmente anticorpos contra o Triypanosoma cruzi.

\section{MATERIAL E MÉTODOS}

\section{PACIENTES}

Esta pesquisa foi realizada em 20 pacientes portadores de doença de chagas, na fase crônica, todos com a reação de Guerreiro-Machado reativa, 11 dentre eles internados no Hospital das Clínicas da Faculdade de Medicina da U.F.M.G., selecionados pelo xenodiagnóstico positivo, para ensaios terapêuticos da doença.

\section{MEIO USADO}

LIT (3) distribuído em dois tubos na quantidade de $5 \mathrm{ml}$ em cada tubo.

\section{COLHEITA, PREPARO E SEMEADURA}

a) Dez $\mathrm{ml}$ de sangue, colhidos com os devidos cuidados de assepsia, (lavagem do antebraço com água e sabão seguida, com o local ainda úmido, de aplicação de éter-acetona e mertiolato) são transferidos, em quantidades iguais $(5 \mathrm{ml})$, para cada um de 2 tubos de centrifuga de $15 \mathrm{ml}$ de capacidade, contendo $1,5 \mathrm{ml}$ de solução de heparina de $5.000 \mathrm{u} .1 . / \mathrm{ml}$, diluída a 6/1000 em soro fisiológico, previamente autoclavados.

b) Os tubos são, em seguida, centrifugados a 3.000 r.p.m. durante meia hora.

o sobrenadante é removido, em condição asséptica, por intermédio de seringa de $10 \mathrm{ml}$ e agulha de $8 \times 80$, tendo-se o cuidado de nạo atingir a camada de plaquetas e leucócitos.

c) São, a seguir acrescentados a cada tubo, em condições assépticas, $5 \mathrm{ml}$ de soro fisiológico previamente autoclavado.

Na medida do possível, o material é homogeinizado e centrifugado novamente, a $3.000 \mathrm{r} . \mathrm{p} . \mathrm{m}$. por 15 minutos.

d) Após remoção do sobrenadante, cuidando ainda em não retirar a camada cie plaquetas e leucócitos, o sedimento é se- meado por intermédio de pipeta de $5 \mathrm{ml}$, em 2 tubos contendo cada um $5 \mathrm{ml}$ de LIT.

e) Os tubos são incubados a $28^{\circ} \mathrm{C}$ e examinados aos 30,45 e 60 dias.

f) $O$ exame microscópico é feito em pequena gota, removida do fundo do tubo, por meio de alça de platina e disposta entre lâmina e lamínula (aumento de x 450).

Após 60 dias, o material dos tubos negativos é centrifugado e o sedimento examinado.

\section{RESULTADOS}

$\mathrm{Na}$ tabela I verifica-se que dos 20 pacientes, $9(45 \%)$ mostraram-se positivos.

Seis $(30 \%)$, dos 20 casos, positivaramse na primeira hemocultura.

Na tabela II são apresentados os resultados dos 20 pacientes variando o número de hemoculturas por paciente. Dezoito, dentre eles, foram submetidos individualmente a entre uma a seis hemoculturas; dos dois restantes, uma paciente submeteu-se a 10 e outra a 14 . Nos casos em que se fez mais de uma hemocultura, as seguintes foram sucessivas, na maioria das vezes, porém nunca colhidas no mesmo dia.

Em 13 pacientes, procedendo a números variáveis de hemoculturas, porém acima de $2(3,4,5,6,10$ e 14), conseguimos posìtivar 6 casos $(46,1 \%)$.

Sete pacientes submetidos também a números variáveis de hemoculturas, porém acima de $3(4,5,6,10$ e 14$)$, mostraram 5 casos positivos $(71,4 \%)$.

A paciente em que fizemos 10 hemoculturas apresentou todas negativas, a em que fizemos 14 apresentou 8 positivas (tabela I).

A tabela III mostra a positividade por tubos; foram obtidos 25 tubos positivos (17\%) no total de 146

Na mesma tabela são apresentadas as variações da positividade por tempo de incubação. Três tubos (12\%) positivaram-se aos 30 dias, $8(32 \%)$ aos 45 dias e $14(56 \%)$ aos 60 dias. A positividade de 6 tubos $(24 \%)$, somente foi obtida após centrifugação do material cultivado.

\section{DISCUSSÃO}

Já estávamos com esse trabalho em andamento, quandn um de nós, Mourão, ini- 


\section{TABELA II}

\begin{tabular}{|c|c|c|c|}
\hline $\begin{array}{l}\text { CULTIVO } \\
\text { PARTIR DO } \\
\text { SANGUIN'EAS } \\
\text { MERO DE HE }\end{array}$ & $\begin{array}{l}\text { DO TRYPA } \\
\text { CONCENTR } \\
\text { AVADAS, } V \\
\text { MOCULTUR }\end{array}$ & $\begin{array}{l}\text { RESUL } \\
\text { VOSOMA } \\
\text { ADO DE } \\
\text { ARIANDO } \\
\text { AS POR }\end{array}$ & $\begin{array}{l}\text { DO DO } \\
\text { RUZI A } \\
\text { ÉLULAS } \\
\text { SE O NÚ- } \\
\text { CIENTE }\end{array}$ \\
\hline \multirow{2}{*}{$\begin{array}{c}\text { Ne } \\
\text { OE HEMOCULTURAS } \\
\text { POR } \\
\text { PACIENTE }\end{array}$} & \multirow{2}{*}{$\begin{array}{l}\text { TOTAL } \\
\text { OE } \\
\text { PACIENTES }\end{array}$} & \multicolumn{2}{|c|}{ RESUITADO / PACIENTE } \\
\hline & & POSITIVO & NEGATIVO \\
\hline 1. & 4 & 1 & 3 \\
\hline 2 & 3 & 2 & 1 \\
\hline 3 & 6 & 1 & 5 \\
\hline 4 & 1 & 1 & 0 \\
\hline 5 & 2 & 1 & 1 \\
\hline 6 & 2 & 2 & 0 \\
\hline 10 & 1 & 0 & 1 \\
\hline 14 & 1 & 1 & 0 \\
\hline
\end{tabular}

ciou com Chiari o estudo de hemoculturas seriadas em meio LIT. O rseultado dessa pesquisa que se acha em publicação (3), ao possibilitar o diagnóstico parasitológico de 13 de 15 pacientes, parece demonstrar que o parasita pode ser cultivado, sistematicamente, a partir do sangue de enfermos crônicos da doença de Chagas e que a positivitade é fator dependente do número de hemoculturas praticadas.

o processo, infelizmente, embora eficiente para demonstrar a parasitemia, é muito trabalhoso. Para obter a positividade dos 13 pacientes, a investigação se estendeu por cerca de um ano; foram examinados 1.337 tubos, por 3 vezes consecutivas (30, 45 e 60 dias), para a obtençāo de 54 tubos positivos $(4 \%)$.

difícil comparar-se a positividade por nós alcançada e a obtida por Chiari e Brener (2). Enquanto o nosso inóculo é constituido pelo concentrado de células de $10 \mathrm{ml}$ de sangue, para a semeadura de 2 tubos, o daqueles autores é constituído pelo sedimento, pelo sobrenadante e por uma fração integral $(1 / 5)$, de $15 \mathrm{ml}$ de sangue de cada paciente.

Comparando-se apenas a positividade que obtivemos em uma única hemocultura, $30 \%$, verificamos que os nossos resultados são superiores porque trabalhamos com menos tubos e fizemos número menor de exames. Enquanto aqueles autores semea- ram 280 tubos e obtiveram 15 positivos $(5,36 \%)$, nós examinamos, no conjunto de hemoculturas dos 20 pacientes, 146 tubos e obtivemos 25 tubos positivos $(17 \%)$.

Pode-se concluir dessa discussão que, embora o trabalho de Chiari e Brener (2) e Mourão e Chiari (8) sejam fundamentais para a demonstração das possibilidades no cultivo do Trypanosoma cruzi, na fase crônica da doença de Chagas, a partir do sangue, são impraticáveis pelo vulto do trabalho que exigem.

O processo ora exposto, a não ser peías dificuldades inerentes ao preparo do LTT, é prático, de execução relativamente fáciī, sendo recomendável para o diagnóstico parasitológico na fase crônica da doença.

Evidentemente seria mais prático a semeadura direta do sangue em meio LIT, porém em experiências anteriores, não publicadas, não fomos capazes de cultivar o tripanosoma, quando empregávamos volumes de sangue, como os $5 \mathrm{ml}$ para cada tubo, da presente experiência. Por esse motivo não incluímos nesta série hemoculturas simultâneas de sangue e concentrado de células. Isto nos impede de concluir se a positividade alcançada resulta de substâncias nocivas ao crescimento, contidas no plasma.

Finalmente, nossas osservações (tabela I) parecem mostrar que a positividade é 


\section{TA B E L A III}

CULTIVO DO TRYPANOSOMA CRUZI A PARTIR DO CONCENTRADO DE CÉLULAS LAVADAS, DO SANGUE DE CHAGA'SICOS CRÓNICOS, EM MEIO LIT.

POS I T I V I DADE POR T U B O

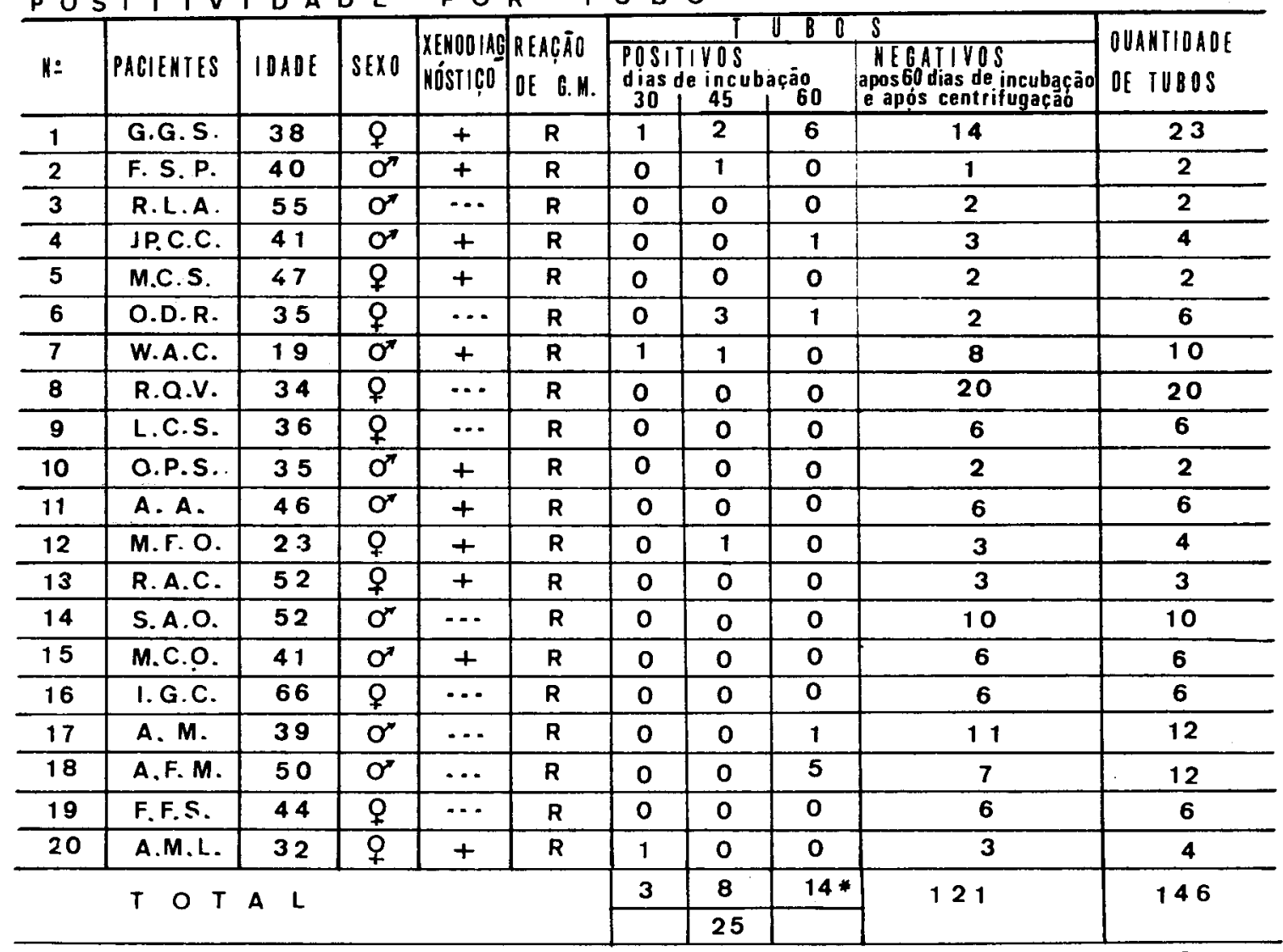

* 6 tubos positivaram-Se no sedimento do material centrifugado

$R=R E A T I V A$

$O=N E G A T I V O$

caráter variável de paciente a paciente. No caso R.Q.V. não obtivemos nenhum resultado positivo apesar de 10 tentativas, enquanto que a paciente G.G.S. apresentou 8 de 14 hemoculturas positivas $(57,2 \%)$, o paciente A. M., 5 de $6(83,3 \%)$ e a pa- ciente O.D.R. mostrou positividade nas 3 hemoculturas a que se submeteu.

\section{AGRADECIMENTOS}

À srta. Maria de Lourdes Ferreira por ajuda técnica.

\section{SUMMARY}

The authors have developed a process to make hemocultures in chronic phase of human Chagas' disease.

They used as inocule the washed packed cells of $10 \mathrm{ml}$ of blood. This material was sampled in 2 tubes of LIT (Liver Infusion Tryptose) with $5 \mathrm{ml}$ of the medium. 
Six positive cases ( $30 \%)$ were detected with only one hemoculture.

Increasing the number of hemocultures (1 to 14) 9 out of 20 cases were positives (45\%). In 7 cases 4 or more hemocultures $(4,5,6,10,14)$ were made and 5 of them were positives $(71,4 \%)$.

The authors recomend the method for routine as a practical and easy method.

\section{REFERÊNCIAS BIBLIOGRAFICAS}

1. ALBUQUERQUE, R. D. R., FERNANDES, L. A. R., FUNAYAMA, G. K., FERRIOLI, F. F. e SIQUEIRA, A. F. -Hemoculturas seriadas com meio de Warren em pacientes com reação de Guerreiro-Machado positiva. Rev. Inst. Med. trop. São Paulo, 14:1-5, 1972.

2. CHIARI, E. \& BRENER, Z. - Contribuição ao diagnóstico parasitológico da Doença de Chagas na fase crônica. Rev. Inst. Med. trop., São Paulo, 8:134-148, 1966 .

3. FERNANDES, J. F. \& CASTELLANI, o. - Perspectiva de vacinação contra a moléstia de Chagas. XVI Reunião anual da S.B.P.C., Ribeirão Preto, São Paulo, 1964.

4. FREITAS, J. L. P. - Contribuição para o estudo do diagnóstico da moléstia de Chagas por processos de laboratório. São Paulo, Faculdade de Medicina da Universidade de São Paulo. 1947. $160 \mathrm{p}$. Tese.

5. FREITAS, J. L. P. - O diagnóstico de laboratório da moléstia de Chagas. Rev. Clín. São Paulo, 28:1-10, 1952.

6. FREITAS, J. L. F. - Processos de laboratório para o diagnóstico da moléstia de Chagas. Rev. Goiana Med. 4:135-147, 1958.

7. MOURÃO, O. G. - Diagnóstico parasitológico da Doença de Chagas na fase crônica. Método para avaliação da terapêutica no homem. Belo Horizonte, Faculdade de Medicina da U.F.M.G., $1966,69 \mathrm{p}$. Tese.

8. MOURÃo, O. G. \& CHIARI E. - Comprovação parasitológica da Doença de Chagas na fase crônica, por hemoculturas seriadas em meio LIT. Rev. Soc. Bras. Med. trop. (in press).

9. PIFANO, F. C. -- El diagnóstico para. sitológico de la enfermedad de Chagas en fase crónica. Estudio comparativo entre la gota gruesa, el xenodiagnóstico, el hemocultivo y las inoculaciones experimentales en animales sensibles. Archiv. Venezol. Patol. Trop. y Parasit. Med. 2:121-152, 1954 